perspective. However, only the trainers not the trainees felt that the new DoC improved educational impact. The main barrier reported to completing both types of assessment was trainer and trainee time.

\section{G178 ABSTRACT WITHDRAWN}

\section{G179 IMPROVING LEADERSHIP AND MANAGEMENT SKILLS IN JUNIOR DOCTORS APPROACHING REGISTRAR LEVEL THROUGH A TRANSITION TO LEADERSHIP COURSE}

1,2LAC Menzies, ${ }^{2,3} \mathrm{SJ}$ Smith, ${ }^{4} \mathrm{~J}$ Moreiras, ${ }^{2,4} \mathrm{CR}$ Fertleman. ${ }^{1}$ Paediatric Department, Barnet General Hospital, London, UK; ${ }^{2}$ Assessment Subgroup, London Specialty School of Paediatrics, London, UK; ${ }^{3}$ Paediatric Department, St Mary's Hospital, London, UK; ${ }^{4}$ Paediatric Department, Whittington Hospital, London, UK

\subsection{6/archdischild-2015-308599.173}

Aims/Background Leadership and management skills are increasingly recognised as fundamental aspects of doctors' clinical practice and drive high-quality, safe healthcare services for patients. However, availability of specific leadership training is limited for junior doctors, with national bodies including the GMC, calling for increased availability of relevant training. We aimed to evaluate the need for and educational impact of a leadership course for paediatric trainees approaching registrar level.

Methods We ran a three day course for thirty paediatric ST3s, entitled 'Transition to Leadership', consisting of two training days in ST3 (SHO) and a third day after trainees had progressed to ST4 (registrar). The course incorporated the NHS Leadership
2014 cohort: Did the course change how you feel about starting as a Registrar?

Yes: $96 \%$ of attendees $(n=26)$

\section{Reasons Why?}

- How to communicate with consultant: feel empowered, know when to do so

- Practical advice on safeguarding, consent and end of life scenarios

- Tips, tools and strategies to cope with challenges/uncertainties

- Feel more confident

- Less anxious, calmer from sharing fears, knowing others felt the same

- Know how to lead the team effectively

- Feel excited/enthusiastic about taking on a new challenge

Reassuring: what the role involves and where to go for support

Reassured about the expectations i.e. not that of an ST8 but of an ST4

Less of an unknown fear

Know how to prepare before starting ST4 and areas to focus on

\section{Abstract G179 Figure 1}

Academy 'Health Leadership Model' and covered areas such as delegation, negotiation, supporting junior trainees and leading at night. In addition, key updates were included on safeguarding, consent and end-of-life care. We collected evaluation data from attendees at three time points: prior to the course, after day two, and after transition to ST4.

Results Paediatric ST3s felt unprepared for the transition to registrar, frequently citing concerns directly related to leadership and management capabilities. Following the course, trainees reported increased competence consistently across eight aspects of leadership and management. Perceived competence in two control aspects not covered on the course was unchanged, indicating a specific effect on leadership skills. Paired t tests demonstrated a significant increase in competence ranking seven of the

Abstract G179 Table 1 Comparing competence rankings before and after the transition to leadership course

\begin{tabular}{|c|c|c|c|c|c|}
\hline Rated Domain & $\begin{array}{l}\text { Pre Course* } \\
(n=30)\end{array}$ & $\begin{array}{c}\text { Post Day } \\
2^{*} \\
(n=26)\end{array}$ & $\begin{array}{c}\text { Post Day } \\
3^{*} \\
(n=13)\end{array}$ & $\begin{array}{l}\text { Mean } \\
\text { Difference in } \\
\text { competence } \\
\text { rating }\end{array}$ & $\begin{array}{l}\text { Paired sample } \\
\text { analysis }(n=24)^{* *}\end{array}$ \\
\hline \multicolumn{6}{|c|}{ Leadership, Management and Communication Domains } \\
\hline Knowing when to call my consultant & $2.9(0.61)$ & $3.5(0.51)$ & $3.5(0.66)$ & +1.6 & $T_{23}=-5.13, P<0.001$ \\
\hline Leading during a resuscitation & $2.2(0.63)$ & $2.5(0.58)$ & $3.0(0.58)$ & +0.8 & $T_{2 y}=-2.30, P=0.03$ \\
\hline Managing conflict & $2.5(0.51)$ & $2.9(0.53)$ & $3.2(0.43)$ & +0.7 & $T_{z}=-2.58, P=0.02$ \\
\hline $\begin{array}{l}\text { Managing cases with safeguarding } \\
\text { concerns }\end{array}$ & $2.3(0.60)$ & $3.2(0.59)$ & $3.2(0.44)$ & +0.9 & $T_{2:}=-5.17, P<0.001$ \\
\hline $\begin{array}{l}\text { Leading on difficult cases regarding } \\
\text { consent }\end{array}$ & $2.2(0.63)$ & $3.0(0.66)$ & $3.1(0.64)$ & +0.9 & $T_{2 y}=-4.70, P<0.001$ \\
\hline $\begin{array}{l}\text { Managing when a child dies on the ward } \\
\text { overnight }\end{array}$ & $1.7(0.52)$ & $2.9(0.69)$ & $3.1(0.86)$ & +1.4 & $T_{2 y}=-6.23, P<0.001$ \\
\hline $\begin{array}{l}\text { Leading and managing a team on a day } \\
\text { to day basis }\end{array}$ & $2.7(0.60)$ & $2.9(0.52)$ & $3.4(0.51)$ & +0.7 & $T_{2 g}=-2.01, P=0.06$ \\
\hline $\begin{array}{l}\text { Making mistakes and coping with } \\
\text { increased responsibility and } \\
\text { accountability }\end{array}$ & $2.2(0.73)$ & $2.7(0.62)$ & $3.3(0.63)$ & +1.1 & $T_{2 y}=-2.77, P=0.01$ \\
\hline \multicolumn{6}{|c|}{ Control Domains } \\
\hline Treating common neonatal problems & $2.9(0.55)$ & $2.9(0.43)$ & $3.0(0.41)$ & +0.1 & $T_{2 y}=-0.57, P=0.57$ \\
\hline Treating common paediatric problems & $3.0(0.41)$ & $2.9(0.39)$ & $3.0(0.41)$ & +0.0 & $T_{2:}=0.57, P=0.57$ \\
\hline
\end{tabular}

-Values shown indicate mean competence ranking across all trainees providing feedback at each stage with standard deviation in parentheses

- Paired sample T test for 24 trainees who attended both Day 1 and Day 2 of the course and completed pre course and post Day 2 feedback forms providing information allowing linking of their feedback forms 
eight leadership domains ( $\mathrm{t} 23<-2.01, \mathrm{P}<0.06$ for the seven domains). This increased competence continued after transition to ST4 indicating a sustained improvement in leadership abilities. Trainees attended all 3 days where possible, allowing them to build rapport with other attendees, creating a safe environment to share and discuss concerns, and to gain peer support and reassurance from group problem-solving sessions (Table 1 and Figure 1).

Conclusions Our Transition to Leadership course was wellreceived by trainees and resulted in significant and sustained improvements in competence across a number of leadership and management domains, demonstrating its potential for longitudinal impact on trainees' performance. We now aim to produce a nationally available comprehensive teaching package and offer faculty training nationally, to make the course accessible to more trainees and expand its educational impact.

\section{G180 EVALUATION OF A NOVEL MENTORSHIP PROGRAMME FOR MEDICAL STUDENTS IN PAEDIATRICS}

1,2B Morrissey, ${ }^{2} \mathrm{P}$ Winyard, ${ }^{1} \mathrm{C}$ Fertleman. ${ }^{1}$ Paediatrics, Whittington Hospital NHS Trust, London, UK; ${ }^{2}$ Institute of Child Health, University College London, London, UK

\subsection{6/archdischild-2015-308599.174}

Background and aims Medical school is a stressful time for many students, who report higher rates of anxiety and depression than the general population. Mentorship can provide increased support to medical students, and improve their academic performance and overall well-being.

We developed and evaluated a novel mentorship programme for third year medical students undertaking an integrated BSc in paediatrics and child health.

Methods The integrated BSc is the first paediatrics-specific BSc in the UK. Mentors were paediatric trainees selected by competitive application; mentors received training prior to starting and ongoing support over the year. Each mentor was matched to one or two mentees and met with them at least two times. Participants were e-mailed an anonymised questionnaire at the end of the programme; responses were analysed thematically.

Results Sixteen medical students and 11 paediatric trainees (mentors) participated in the programme. Eighty six percent of mentees would recommend the programme to other students with $43 \%$ reporting that it was 'very helpful' and 43\% 'a bit helpful.' Thematic analysis of free text responses identified four major benefits: personal support, feedback on assessments, guidance on paediatrics as a career, and advice on life issues outside medicine.

$100 \%$ of the mentors would recommend the programme to their colleagues. $88 \%$ thought it had 'definitely been helpful' for their future career in paediatrics. They identified four main benefits: Skills and experience in mentorship, practice providing support to junior colleagues "very helpful for future roles such as becoming an educational or clinical supervisor", a greater understanding of the undergraduate experience, and approaching paediatrics through fresh eyes. Mentors found it enjoyable and rewarding: "It gave me a lot of satisfaction." Challenges included finding the time to meet students and "worrying that the students did find it useful."

Conclusions Our novel mentorship programme utilised current paediatric trainees to enthuse and mentor potential future paediatricians. There were bilateral benefits to both mentors and mentees. We anticipated that students would gain from the experience, but it was also highly valuable to the paediatric trainees who developed transferable skills in mentorship and supervision, both essential but difficult to achieve competencies in the paediatric training curriculum.

\section{G181(P) REFLECTIONS ON SAFEGUARDING TRAINING: WHAT NEW SKILLS DO PAEDIATRIC TRAINEES VALUE?}

${ }^{1} \mathrm{KH}$ Fawbert, ${ }^{1} \mathrm{D}$ James, ${ }^{2} \mathrm{P}$ de Keyser, ${ }^{3} \mathrm{CR}$ Fertleman. ${ }^{1}$ Medical Education, London School of Paediatrics, UK; ${ }^{2}$ General Paediatrics, Royal Free London NHS Foundation Trust, UK; ${ }^{3}$ General Paediatrics, The Whittington Hospital, London, UK

\subsection{6/archdischild-2015-308599.175}

Aims Providing effective safeguarding training to paediatric trainees is vital. The RCPCH approved 'Child Protection Recognition and Response Course' utilises pre-course and face-to-face components with role play communication scenarios, and assessment by senior paediatricians. We aimed to investigate common themes in learning which were beneficial in skill acquisition.

Methods 82 paediatric trainees participating in the 'Child Protection Recognition and Response Course' were given anonymous pre-course questionnaires and an on-line questionnaire six weeks afterwards. Four questions were posed utilising Likert scales, with an additional post-course free text question (Table 1, responses, Table 2, confidence scores and Table 3, most common themes).

Conclusions Trainees had lowest perceived confidence scores in communicating safeguarding concerns with caregivers, and in relevant referral and legal processes. These were the two areas with the greatest improvement in mean confidence score after the course, although there was clear improvement in all domains. Additionally this was mirrored in the most frequent themes of valued learning: useful approaches when speaking to

\begin{tabular}{|c|c|c|}
\hline Grade & Pre-course respondents & Post-course respondents \\
\hline ST1 & $17(23 \%)$ & $4(14 \%)$ \\
\hline ST2 & $28(37 \%)$ & $8(29 \%)$ \\
\hline ST3 & $12(16 \%)$ & $2(7 \%)$ \\
\hline ST4 & $13(17.5 \%)$ & $11(39 \%)$ \\
\hline Other & $5(6.5 \%)$ & $3(11 \%)$ \\
\hline Total & $75 / 82(91 \%)$ & $28 / 82(34 \%)$ \\
\hline
\end{tabular}

Abstract G181(P) Table 2 Confidence scores

\begin{tabular}{|c|c|c|c|}
\hline Question & $\begin{array}{l}\text { Mean } \\
\text { pre-course } \\
\text { score (1-5) }\end{array}$ & $\begin{array}{l}\text { Mean } \\
\text { post-course } \\
\text { score (1-5) }\end{array}$ & $\begin{array}{l}\text { Change } \\
\text { in score }\end{array}$ \\
\hline $\begin{array}{l}\text { How confident do you feel about being able } \\
\text { to identify the physical signs of child abuse? }\end{array}$ & \multicolumn{3}{|c|}{ How confident do you feel about being able } \\
\hline \multicolumn{4}{|l|}{$\begin{array}{l}\text { How confident do you feel about being able } \\
\text { to identify the non-physical signs of child }\end{array}$} \\
\hline abuse? & 2.8 & 3.8 & 1.0 \\
\hline \multicolumn{4}{|l|}{$\begin{array}{l}\text { How confident do you feel when talking to a } \\
\text { parent about child safeguarding concerns }\end{array}$} \\
\hline you have about their child? & 2.6 & 3.8 & 1.2 \\
\hline \multicolumn{4}{|l|}{$\begin{array}{l}\text { How would you rate your knowledge about } \\
\text { social services and legal processes relevant }\end{array}$} \\
\hline to child safeguarding situations? & 2.6 & 4.0 & 1.4 \\
\hline
\end{tabular}

